\title{
Adult Fanconi syndrome and multiple myelomatosis
}

\author{
MAR GARET E. HORN, M. S. KNAPP, F. T. PAGE, AND W. H. C. WALKER \\ From Bristol Royal Infirmary and Frenchay Hospital, Bristol
}

SYNOPSIS A case is described of a 59-year-old woman presenting with multiple renal tubular defects $\overrightarrow{\vec{\omega}}$ The aminoaciduria was of a generalized type. When investigated initially the only feature of myelomatosis was urinary Bence-Jones protein. Two years later radiologically classical multiplę? myelomatosis developed and rapidly progressed to the patient's death nine months later.

The coexistence of myelomatosis and the Fanconi syndrome has previously been described. Harrison and Blainey (1967), in a review of the world literature, cite seven examples and add two of their own cases in which the adult Fanconi syndrome was associated with abnormality of the immune globulin light chain. We present here a further example with comments on the peculiarities of the combined disorder, and a detailed account of serum and urine levels of amino acids.

\section{CASE REPORT}

Mrs D.J., a 59-year-old housewife, presented in May 1964 with a nine-month history of back pain radiating around the trunk with stiffness and aching of the hips and legs. She had noticed an abnormality of gait, which tended to be waddling, and pain in the left foot which made weight bearing difficult. These symptoms had recently become worse and interfered with her employment as a part-time games mistress. For two years she had been abnormally tired. Physical examination was negative apart from very brisk tendon reflexes in the legs. Despite the absence of definite abnormal neurological signs a provisional diagnosis of a very early paraparesis with nerve root pressure at T 7 to 8 was suspected. Myelography was performed and was normal. It was noted that she had proteinuria and glycosuria in an alkaline fasting urine. The results of further investigations and those of subsequent admissions are given in Tables I and II. In summary she had renal glycosuria with a renal threshold of less than $100 \mathrm{mg} \%$, proteinuria, and generalized aminoaciduria. Serum electrolytes showed a hyperchloraemic acidosis. The plasma phosphate level of $2 \cdot 8$ $\mathrm{mg} \%$ was at the lower limit of normal and the serum calcium level was $9.6 \mathrm{mg} \%$ with increased urinary calcium excretion. The alkaline phosphatase level was slightly raised at $18 \mathrm{~K}$-A units. Radiographs of the lumbar and dorsal spine and of the skull were normal. A bone biopsy was not performed. The urinary protein was Received for publication 3 September 1968. examined by one- and two-way starch electrophoresis in July 1964 and showed some typical components of tubular protein and in addition bands like a Bence-Jones protein. She was therefore diagnosed as having an adult form of the Fanconi syndrome although evidence ofo osteomalacia was minimal. There was no family historye of this condition or of renal disease and no parentaib consanguinity. It was thought that there could well be associated myelomatosis. Treatment was started with vitamin $\mathrm{D}$ and calcium lactate, and there was a striking improvement in all her symptoms, except for fatigueo which persisted.

In July 1965 serum and urine immunoelectrophoresis $\overrightarrow{7}$ was performed and showed free light chains in the serum? and Bence-Jones proteinuria.

In September 1966 the back pain became worse. The patient had become weak, tired, and had lost $1 \mathrm{~kg}$ in weight. On examination she was now pale and hads developed a slight dorsal kyphoscoliosis with tendernesson percussion over the lower spine and ribs. Investigation?

\section{TABLE I}

\begin{tabular}{ccccc}
\multicolumn{9}{c}{ T A BLE I } & & \\
May & Sept & Nov & Jan \\
1964 & 1966 & 1966 & 1967 \\
\hline
\end{tabular}

\section{Blood}

Urea (mg/100 ml)

Sodium (m-equiv/l)

Potassium (m-equiv/l)

Chloride (m-equiv/l)

Bicarbonate (m-equiv/1)

Calcium (mg/100 ml)

Phosphorus (mg/100 ml)

Alkaline phosphatase

(K-A units)

Total protein $(\mathrm{g} / 100 \mathrm{ml})$

Albumin $(\mathrm{g} / 100 \mathrm{ml})$

IgA (mg/100 ml)

$\operatorname{IgG}(\mathrm{mg} / 100 \mathrm{ml})$

$\operatorname{IgM}(\mathrm{mg} / 100 \mathrm{ml})$

Uric acid $(\mathrm{mg} / 100 \mathrm{ml})$

ESR (mm/hr, Wintrobe)

$\mathrm{Hb}(\mathrm{g} / 100 \mathrm{ml})$

$\begin{array}{cclc}28 & 25 & 28 & 30 \\ 133 & 136 & - & 132 \\ 3.5 & 3.4 & - & 2 \cdot 1 \\ 108 & 106 & - & 97 \\ 15.6 & 19 \cdot 5 & - & 22.5 \\ 9.6 & 11.0 & 9 \cdot 3 & 10.4 \\ 2.8 & 2.4 & 1.8 & 1 \cdot 3 \\ 18 & 22 & - & 21 \\ 6.3 & 6 \cdot 1 & 7.0 & 6.8 \\ 3.6 & 3.6 & 3.6 & 3.6 \\ - & 45 & - & 45 \\ - & 840 & - & 560 \\ - & 15 & - & 20 \\ 2.2 & 1.1 & - & 1.6 \\ 8 & 18 & 22 & 55 \\ 12.4 & 12.2 & 12.5 & 9.4 \\ & & & \end{array}$

Urine

Calcium (mg/day)

穴 
TABLE II

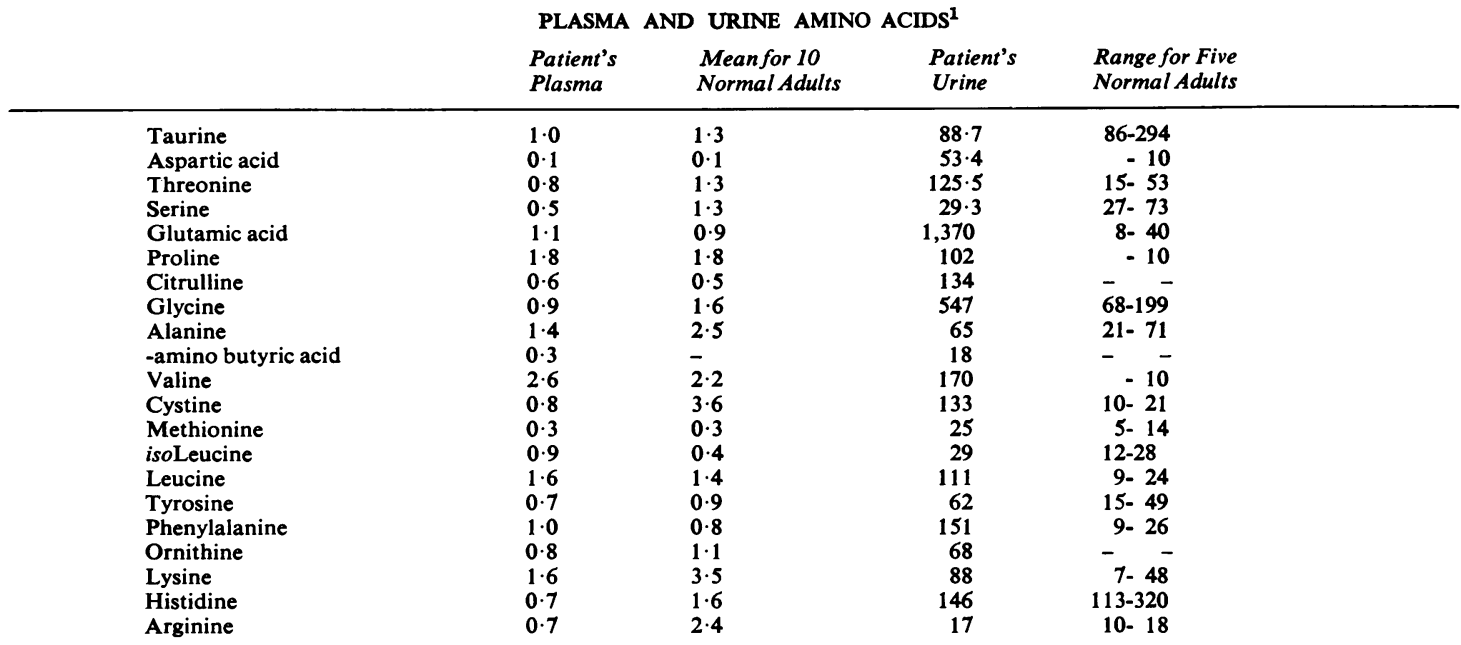

${ }^{1}$ Estimations were made by Technicon amino-acid analyser in January 1967 by Dr J. Holden. Amino acid content of plasma (mg/100 ml) and urine $\mathrm{mg} / 24$ hours.

again showed evidence of a renal tubular defect. The serum uric acid level was found to be very low. The plasma phosphate level had fallen to $2.4 \mathrm{mg} \%$ and the alkaline phosphatase level had risen to $22 \mathrm{~K}$-A units. Bence-Jones protein (type $\mathrm{K}$ ) was now present in large amounts (10 to $20 \mathrm{~g}$ per day) in her urine. The immune globulins, including $\operatorname{IgD}$, were at or below the lower limit of normal and free light chains (type $\mathrm{K}$ ) were again demonstrated in the serum. Round lytic lesions, typical of multiple myeloma, were visible on the skull radiograph. There was also a generalized decrease in bone density of the spine, with fractures of the eighth and ninth ribs which could have been due to multiple myeloma or to osteomalacia. The bone marrow showed a few morphologically abnormal plasma cells. These findings suggested that some of her symptoms were now due to multiple myelomatosis. She was treated with cyclophosphamide and improved. The pain recurred in November 1966 so prednisone and localized radiotherapy were added to the treatment.

By January 1967 her condition had markedly deteriorated with a loss in weight of $2 \mathrm{~kg}$ over four months; the sternum had caved in and chest movements were paradoxical. Radiographs showed multiple new and old rib fractures with marked sternal deformity and collapse of several mid-dorsal vertebrae. She died at home in March 1967. A necropsy was not performed.

\section{DISCUSSION}

This case is presented because the combination of myelomatosis and the Fanconi syndrome is rare and the previously reported examples lack the data on immune globulins and amino acid clearance that can now be obtained.
The diagnosis of multiple myelomatosis is not always clear cut. Hällen (1966) and Hobbs (1967) have discussed the criteria needed to make the diagnosis. They agree that the diagnosis is supported by finding radiological evidence of osteolytic lesions, an excess of atypical plasma cells in the bone marrow, the presence of an abnormal globulin band on serum electrophoresis, or Bence-Jones proteinuria. Hällen emphasized the importance of radiological evidence of osteolytic lesions for which no other cause could be found, but Hobbs did not consider these changes to be essential in making the diagnosis. According to the criteria of both authors the present patient had multiple myelomatosis.

A variety of renal tubular defects has been described in association with myelomatosis. In some cases aminoaciduria and glycosuria were noted (Engle and Wallis, 1957; Short and Smith, 1959; Costanza and Smoller, 1963); in others these defects occurred with evidence of osteomalacia of renal origin as well (Sirota and Hamerman, 1954; Dragsted and Hjorth, 1956; Muntendam, 1958). The term 'adult Fanconi syndrome' is best confined to the latter group to conform with the original description of Fanconi (1936). Although this condition is associated with tubular defects greatly in excess of any glomerular dysfunction, the presence of a raised blood urea level does not exclude the diagnosis of the Fanconi syndrome because an entirely independent glomerular disorder may be superimposed, eg, as a result of the other types of renal disorder described in myelomatosis (Harvey, Walker, and Yardley, 1963). In the present case 
there was evidence of multiple renal tubular defects in the absence of azotaemia.

The analysis of blood and urine amino acids (Table II) showed that the aminoaciduria was of a generalized type with increased clearances affecting all transport systems (Milne, 1964), indicating nonspecific tubular malfunction.

Harrison and Blainey review seven cases of renal tubular disorder accompanying multiple myeloma. They include the case reported by Dedmon, West, and Schwartz (1963) which had cirrhosis with a diffuse increase in gamma globulin containing $12 \%$ macroglobulin. In our opinion there is insufficient evidence to support a diagnosis of myelomatosis in their case. In the other six cases there was evidence either of typical multiple myelomatosis or of 'essential hyperglobulinaemia' (Waldenström, 1952).

The two cases of Harrison and Blainey are unusual because Bence-Jones proteinuria occurred without serum abnormalities or other evidence of myelomatosis. They suggest that these cases may represent 'benign essential Bence-Jones proteinuria' in association with the Fanconi syndrome. These authors concluded, after their review of the literature, that the complete Fanconi syndrome had not presented as a complication of radiologically classical multiple myeloma and had been con- sistently associated with a relatively benign course of $\stackrel{\text { 을 }}{\vec{*}}$ the myeloproliferative disorder.

The present case is an example of a patient $\overrightarrow{\vec{D}}$ presenting with multiple renal tubular defects associated with Bence-Jones proteinuria. Two years $\frac{}{0}$ later radiologically classical multiple myelomatosis $\frac{\overline{\bar{s}}}{2}$ developed and rapidly progressed until the patient's $\stackrel{\otimes}{Q}$ death nine months later.

We are grateful to Dr J. E. Cates for permission to $\vec{\circ}$ publish this case. We would also like to acknowledge biochemical assistance from Dr J. Holden, Dr G. R. $\vec{\omega}$ Philpot, Dr D. Rowe, Dr F. V. Flynn, and Dr J. V. Jones.

\section{REFERENCES}

Costanza, D. J., and Smoller, M. (1963). Amer. J. Med., 34, 125. Dedmon, R. E., West, J. H., and Schwartz, T. B. (1963). Med. clin. N. $\frac{1}{1}$

Dragsted, P. J., and Hjorth, N. (1956). Dan. med. Bull., 3, 177. Engle, R. L., Jr, and Wallis, L. A. (1957). Amer. J. Med., 22, 5. Fanconi, G. (1936). Dtsch. med. Wschr., 62, 1169.

Hällén, J. (1966). Acta med. scand., suppl. 462, 14.

Harrison, J. F., and Blainey, J. D. (1967). J. clin. Path., 20, 42. Harvey, A. M., Walker, W. G., and Yardley, J. H. (1963). In Diseases of the Kidney, edited by M. B. Strauss and L. G. Welt, p. 575. Churchill, London. Little, Brown, Boston.

Hobbs, J. R. (1967). Brit. med. J., 3, 699

Milne, M. D. (1964). Ibid., 1, 327.

Muntendam, H. (1958). Ned. T. Geneesk., 102, 1690.

Sirota, J. H., and Hamerman, D. (1954). Amer. J. Med., 16, 138.

Short, I. A., and Smith, J. P. (1959). Scot. med. J., 4, 89.

Waldenström, J. (1952). Advanc. intern. Med., 5, 398. 